Revista Brasileira

de Estudos de

Cinema

e Audiovisual

\title{
O novo cinema português e o cinema novo brasileiro:
}

o caso Glauber

Paulo Cunha ${ }^{1}$

${ }^{1}$ Paulo Cunha é doutor em Estudos Contemporâneos pela Universidade de

Coimbra. Leciona Cinema na Universidade da Beira Interior. É pesquisador integrado do LabCom.IFP da Universidade da Beira Interior e da Rede Proprietas. É Coordenador Editorial da Aniki: Revista Portuguesa da Imagem em Movimento. Tem publicado diversos textos sobre cinema português, cineclubismo e cinema de amadores, políticas públicas e modos de produção.

e-mail: paulomfcunha@gmail.com 


\section{Resumo}

Este breve texto pretende fazer uma aproximação entre o novo cinema português e o cinema novo brasileiro a partir das pontes estabelecidas pelo cineasta brasileiro Glauber Rocha com diversos cineastas portugueses. Sabendo que, desde meados dos anos 60 até à sua morte, Glauber Rocha manteve relações de amizade e cumplicidade cinéfila com várias figuras do novo cinema português, pretendo saber se o cineasta brasileiro terá sido um elemento fundamental no diálogo entre os cinemas brasileiro e português desse período.

Objetivamente, o que pretendo fazer, a partir de um estudo de caso concreto, é iniciar um levantamento arqueológico das relações entre o cinema novo brasileiro e o novo cinema português. Interessa-me também conhecer e tentar refletir sobre a forma como estes dois novos cinemas que se expressavam através da língua portuguesa se posicionaram nos circuitos cinéfilos internacionais que defendiam um cinema como forma de expressão artística e cultural e como experiência moderna.

Palavras-chave: Novo cinema português; Cinema novo brasileiro; Glauber Rocha; Cinema Tricontinental.

\section{Abstract}

This short text intends to make an approximation between the new Portuguese cinema and the Brazilian new cinema from the bridges established by the Brazilian filmmaker Glauber Rocha with several Portuguese filmmakers. Knowing that, from the mid-1960s until his death, Glauber Rocha maintained relations of friendship and cinematic complicity with various figures of the new Portuguese cinema, I want to know if the Brazilian filmmaker would have been a fundamental element in the dialogue between the Brazilian and Portuguese theaters of that period.

Objectively, what I intend to do, starting from a concrete case study, is to begin an archaeological survey of the relations between the Brazilian new cinema and the new Portuguese cinema. It is also my interest to know and try to reflect on how these two new cinemas that expressed themselves through the Portuguese language have positioned themselves in the international cinephile circuits that defended a cinema as a form of artistic and cultural expression and as a modern experience.

Keywords: New Portuguese cinema; Brazilian new cinema; Glauber Rocha; Tricontinental Cinema. 
Que relações pessoais ou profissionais se conhecem entre cineastas dos dois países? Que condições de recepção e divulgação, por parte do público e da crítica, conheceram os filmes no país-irmão? Que influências estéticas e éticas terão exercido um cinema sobre o outro? Os modos de produção de um terão sido exemplo ou inspiração para o outro? Os processos de afirmação e reconhecimento, quer no interior como no exterior, terão sido similares?

Estas são algumas perguntas que urge primeiro fazer e depois tentar elaborar respostas para contribuir para um estudo comparativo das duas cinematografias que possa ajudar a compreender melhor as suas dinâmicas de afirmação e reconhecimento nos circuitos cinéfilos internacionais.

São reconhecidas pelos próprios jovens cineastas do novo cinema português diversas afiliações e influências estéticas e éticas estrangeiras que contribuíram para o esforço de renovação no cinema português de então. Num inquérito promovido pela Cinemateca Portuguesa em 1985, a propósito da primeira retrospectiva dedicada ao novo cinema português, uma das principais questões dizia respeito às influências de cinematografias estrangeiras: "Considera que os seus filmes (tanto ao nível da produção, como ao nível estético) se filiam, ou foram influenciados, em movimentos internacionais?". Na sua resposta, Fernando Lopes cita uma máxima popularizada por Glauber Rocha como inspiração: "câmera na mão e pé no chão". Ainda assim, as principais referências internacionais assumidas vinham das novas ondas europeias.

Desde finais dos anos 50 , primeiro com bolsas de estudo financiadas pelo próprio Estado Português e depois por instituições privadas como a Fundação Calouste Gulbenkian, grande parte dos jovens que institucionalizariam mais tarde o novo cinema português frequentou escolas de cinema um pouco por toda a Europa, particularmente em Londres e Paris. Nessas escolas, a generalidade dos alunos receberam dois importantes núcleos de influência: a) herança cinéfila de autores clássicos europeus como Jean Renoir, Carl Theodor Dryer, Fritz Lang, 
Sergei Eisenstein ou Roberto Rosselini, mas também americanos (Orson Welles, Nicholas Ray, John Ford, Alfred Hitchcock) e orientais (Ozu, Mizoguchi); b) a prática de jovens cineastas que um pouco por toda a Europa propunham o cinemas das new waves (os franceses François Truffaut, Jean-Luc Godard ou Claude Chabrol, os ingleses Lindsay Anderson, Karel Reicz ou Tony Richardson, e os italianos Michelangelo Antonioni, Federico Fellini ou Pier Paolo Pasolini).

Apesar de ser falado numa língua comum, e essencialmente por razões duma certa periferia geográfica e cultural do Brasil, o cinema brasileiro - velho ou novo não estava presente entre as referências cinéfilas dos jovens cineastas portugueses até meados dos anos 60. Mas na segunda metade da década, sobretudo após a falência das Produções António da Cunha Telles, quando os jovens cineastas procuraram redefinir as suas estratégias de afirmação e apostaram definitivamente na internacionalização, o cinema novo brasileiro serviu como exemplo de acção para vários cineastas portugueses.

Por partir de um contexto cultural periférico semelhante ao português e ter conseguido triunfar no circuito cinéfilo internacional - Deus e o Diabo na Terra do Sol e Terra em Transe, ambos de Glauber Rocha, foram premiados em Cannes (1964 e 1967, respectivamente); Vidas Secas, de Nelson Pereira dos Santos, foi premiado em Cannes (1964), e Fome de Amor em Berlim (1968); Os Fuzis, de Ruy Guerra, foi premiado em Berlim (1964) -, o cinema novo brasileiro foi visto como um exemplo de sucesso e um modelo a seguir pelos jovens cineastas portugueses, até porque partilhavam de muitas premissas estéticas.

2.

Apesar de aplaudido nos festivais e pela crítica especializada europeia, o cinema novo brasileiro continuava longe das salas de cinema portuguesas. De acordo com o levantamento de SILVA (2006), só nos anos 70 é que os filmes brasileiros começaram a ser verdadeiramente exibidos em Lisboa, sobretudo em retrospectivas e mostras $\left(1^{\circ}\right.$ Festival de cinema Brasileiro em 1971; $1^{\text {a }}$ Retrospectiva do Cinema Brasileiro, 1972; Semana do Cinema Brasileiro, 1973). 
Ao longo dos anos 60, salvo raras exceções, como 0 pagador de promessas, Assalto em trem pagador ou Vidas Secas, a censura e a falta de interesse dos distribuidores portugueses não permitiram a divulgação do cinema brasileiro em Portugal. Por exemplo, Antônio das Mortes (1969) só seria exibido com cortes em 1972 (CELULÓIDE, 1974: 19), e Deus e o Diabo na Terra do Sol e Terra em Transe só chegariam às salas portuguesas depois da Revolução de 1974.

No entanto, como observa Regina Silva, a crítica cinematográfica portuguesa reconhecia as qualidades do cinema novo brasileiro e a necessidade de exibi-lo em Portugal, mas também a necessidade de divulgar o novo cinema português em terras brasileiras:

Em Junho de 1966 o editorial da Celulóide clamava por um Cinema Novo luso-brasileiro. Com uma frase de efeito persuasivo logo nas primeiras linhas: o Cinema Novo é um fenômeno universal, o texto não só acolhe o Cinema Novo brasileiro, mas clama por uma partilha entre este movimento e o Novo Cinema português: Em Portugal e no Brasil, um Cinema Novo de língua portuguesa, fala uma linguagem universal e vai, com certeza, vencer. Comparando Verdes anos de Paulo Rocha, Belarmino de Fernando Lopes, Catembe de Faria de Almeida, Domingo à tarde de António de Macedo com Deus e o diabo na terra do sol de Glauber Rocha, Os fuzis de Ruy Guerra, ou Vidas secas de Nelson Pereira dos Santos, o editorial defende um Cinema Novo Luso-Brasileiro e apela aos distribuidores por uma exibição mútua de filmes portugueses no Brasil e brasileiros em Portugal. A identificação (ainda que isto provoque questionamentos) e o acolhimento da cinematografia brasileira pela revista revelam a boa imagem que o cinema brasileiro detinha em território luso no período, além, naturalmente da proposta de promoção do movimento cinemanovista (SILVA, 2006: 141).

Em 1965, a Seara Nova publicou "Descoberta dos Cinemas da Fome", onde o Cinema Novo brasileiro era encarado como uma verdadeira revolução, comparável à do neo-realismo na Itália. O texto acentua o caráter de compromisso social e autenticidade do movimento que busca defender as raízes nacionais e refletir sobre o "cinema da fome", numa clara alusão ao manifesto de Glauber Rocha. Apesar de demonstrar certo desconhecimento nos dados apresentados (como chamar Ruy Guerra de um realizador negro e afirmar que no Brasil há uma 
ausência de preconceitos raciais), Michel Capdenac mostrou sua defesa de um cinema contemporâneo, de vanguarda estética e política, cinema este que "já contrastava com o declínio artístico das cinematografias mais desenvolvidas, um cinema da fome". (SILVA, 2006: 148)

3.

Apesar de algumas relações pessoais estabelecidas por estes anos entre vários jovens cineastas portugueses e Glauber Rocha, não se conhecem óbvias influências estéticas sobre filmes dos jovens cineastas portugueses.

A exceção é claramente Paulo Rocha. Conheceu Glauber em Cannes (1964), e voltariam a encontrar-se em Acapulco (1965) e Montreal (1967). O seu segundo longa-metragem - Mudar de Vida (1966) - foi protagonizado pelo brasileiro Geraldo d'el Rey (por sugestão direta de Glauber), e era ambientado numa comunidade de pescadores do norte do país, num cenário marcadamente precário do ponto de vista social, e próximo do nordeste brasileiro. Fernando Lopes, António da Cunha Telles e José Fonseca e Costa também se relacionaram com Glauber, mas os seus filmes não refletem influências estéticas óbvias.

Na minha opinião, é na fase final do novo cinema português (1974-80) que parece mais presente uma influência do pensamento de Glauber Rocha sobre os cineastas deste movimento. Em 1974, no dia seguinte à Revolução, Glauber chegou a Portugal. Nos dias 28 e 29 de abril, Glauber esteve presente numa importante reunião que teve lugar no anterior Sindicato Nacional dos Profissionais de Cinema para apoiar o plano de ação da Comissão de Cineastas Anti-Fascistas e para dar testemunho de outras experiências paralelas que tão bem conhecia, nomeadamente no Brasil, Chile, México e Cuba.

Glauber Rocha foi o único estrangeiro convidado a colaborar no filme coletivo As Armas e o Povo (1975), um documentário assinado por um coletivo de "Trabalhadores da Atividade Cinematográfica", que registrava os primeiros dias de liberdade de um povo a viver os primeiros dias de processo revolucionário, mais concretamente os eventos registrados entre os dias 25 de abril e $1^{\circ}$ de maio de 
1974. Este convite espelha bem a importância do cineasta brasileiro num momento de redefinição da instituição cinema em Portugal.

Numa entrevista conduzida por João César Monteiro, então publicada na revista Cinéfilo de 18 de Maio de 1974, Glauber teceu algumas considerações sobre o singular momento que o cinema português atravessava e sobre o panorama internacional da distribuição cinematográfica.

Nessa entrevista, Glauber Rocha incluía o novo cinema português, tal como o cinema novo brasileiro, no que ele designava por "cinema independente", uma espécie de terceira via que se distinguia ideologicamente dos cinemas produzidos por duas grandes "estruturas econômicas" hegemônicas: "de um lado o cinema capitalista, cujo modelo expressivo é o cinema hollywoodiano (...); temos depois uma segunda estrutura - a dos países socialistas - que é a indústria estatal (...)" (Glauber Rocha apud MONTEIRO, 1974: 11).

Neste momento singular, a contribuição de Glauber foi reconhecida como importante para o futuro do cinema português que então se discutia e procurava construir. No entanto, tal como aconteceu noutros países, com experiências "geralmente falhadas por falta de rigor e disciplina na formulação dos problemas e na definição de uma linha de reivindicações coletiva", também em Portugal a conjectura social e política não permitiu a afirmação de um cinema verdadeiramente revolucionário como Glauber preconizava (lbid., p. 10). Gradualmente, com o "aburguesamento" do processo revolucionário em curso, as ambições e os limites do cinema português voltavam ao momento anterior à revolução.

Em julho desse ano, Glauber voltou a Paris; e após cinco anos de exílio, regressou ao Brasil. Mas, em 1981, após uma viagem a Itália para apresentar $A$ Idade da Terra (Veneza, 1981), Glauber não aceitou a má recepção crítica ao filme no Brasil e, também motivado pelo esforço de renovação sobrevivente no cinema português, decidiu rumar a Portugal. Regressou então em fevereiro de 1981, e instalou-se em Sintra, cidade especial para Glauber pela ligação ao universo metafísico de Eça de Queirós. Em abril do mesmo ano, a Cinemateca Portuguesa dedicou-Ihe uma retrospectiva. 
Anos antes, com O leão de sete cabeças (Congo, Itália, França, 1970), Cabeças cortadas (Espanha, 1970) e História do Brasil (Cuba, Itália, 1972-74), Glauber Rocha tentou desenvolver um projeto "de integração política e estética das cinematografias dos países pobres dos três continentes (América Latina, África e Ásia)" a que denominou de "Cinema Tricontinental, inspirado no internacionalismo revolucionário de Che Guevara." (CARDOSO, 2007: IV). No discurso de Glauber Rocha, as primeiras referências ao "Cinema Tricontinental" surgiram em textos de 1967. A expressão ganhou maior visibilidade numa entrevista publicada em janeiro de 1968 pela francesa Positif: uma verdadeira relação internacional que se deveria "pautar num princípio de equivalência entre culturas: basta de paternalismo, basta de solidariedade sentimental, basta de humilhação, basta de agressividade gratuita, sobretudo, baste de conselhos". (Ibid., p. 23-26).

Entre 1967 e 1974, através de declarações, intervenções e dos próprios filmes, Glauber Rocha foi construindo uma ideia de Cinema Tricontinental que foi orientando a sua ação política e a sua reflexão:

(...) contribuiu para a definição clara de um patamar de interlocução com a crítica europeia: apontou formas de aglutinação das cinematografias latinoamericanas esboçando um projecto de descolonização estética e de combate à linguagem do cinema hollywoodiano; convergiu, enfim, estética e política, cinema e experiência na realização de alguns filmes, cuja expressão cinematográfica radical foi capaz de romper com os padrões de colonialidade e incorporar as forças mágicas das culturas populares. (Ibid.)

A vinda de Glauber Rocha a Portugal para viver a revolução in loco coincidiu com este período de reflexão sobre o Cinema Tricontinental. O fim de uma ditadura fascista que durava 48 anos fez Glauber Rocha olhar para Portugal com outros olhos, inclusive como espaço para desenvolver algum projeto cinematográfico. Entre 1974 e 1981, dos inúmeros projetos que desenvolveu, Glauber pensava em alguns que poderiam ter como parceiros cineastas portugueses, um dos quais Fernando Lopes: 
Rocha. O Belarmino chegou a passar no festival de Pésaro clandestinamente. O primeiro festival de cinema novo... quando o Glauber Rocha ganhou o prêmio com o Barravento e o prêmio de crítica ficou para mim com o Belarmino. E aí ficamos muito amigos, tivemos imensas relações, eu e o Gláuber, sobretudo em Paris, e depois aqui em Lisboa já na fase final do Glauber, quando eu era diretor de co-produções, já muito depois do 25 de Abril, eu fui diretor de co-produções do serviço público. E aí tínhamos a idéia de fazer um filme, que se chamava Uma Cidade Qualquer, que depois que ele morreu eu dei a mãe dele... (Fernando Lopes, apud SALES, 2009: 31).

Mas segundo Mário Pacheco, Glauber tinha projetos bem mais ambiciosos:

O objetivo principal dessa renovação é a criação de uma cinematografia de língua portuguesa, aberta, portanto, ao Brasil e a África, que depende da efetização de um acordo luso-brasileiro... Esse projeto é também a concretização do tricontinentalismo que Glauber Rocha defende. Um novo movimento de cinema com a livre circulação dos filmes brasileiros e portugueses que, extrapolando, abrangeria o mundo de fala portuguesa" (PACHECO, s/d).

Glauber Rocha estaria particularmente entusiasmado com um acordo de coprodução cinematográfica entre Portugal e Brasil assinado em 3 de fevereiro de 1981, mas que só seria publicado em Portugal em 21 de abril seguinte (decreto regulamentar 48/81), e no Brasil apenas em 14 de junho de 1985 (decreto 91.332/85).

Como reza o texto do acordo, os dois governos, "animados pelo propósito de difundir, através da coprodução de filmes, o acervo cultural dos dois povos" e "pelo objetivo de promover e incrementar os interesses comerciais das indústrias cinematográficas respectivas com base na igualdade de direitos e benefícios mútuos", decidiram considerar como nacionais nos dois países os filmes de longa-metragem concluídos em regime de coprodução, e autorizar, sem quaisquer restrições, a exploração comercial desses filmes nos dois países.

Nesse período, Glauber escreveu em várias correspondências com amigos (BENTES, 1997) alguns dos seus planos cinematográficos: 
Paris, 29-30/dezembro de 1980 / Querido Celso [Amorim, diretor da Embrafilme] / (...) Manifestei-lhe o desejo de fundar uma Empresa de Comunicações em Paris (com ramal em Lisboa) e dar início à minha produção.

Sintra, 23 de março de 1981. / Cacá [Diegues], / (...) Assinei um contrato para escrever um roteiro e tenho como viver até junho, meados de julho, quando espero concretizar a produção. Aqui há condições, o ambiente é tranquilo, tenho alguns amigos (...) Se nada der certo, verei onde posso fazer este filme que estou criando, ou outro, em outro país, sem excluir o Brasil. / Vivo um intervalo. Fim de um ciclo psíquico e corporal. Um segundo exílio, de futuro incerto, mas caminhos mais ou menos estruturados. (...) / Não lamento nada. Este túnel chegará ao fim e nos encontraremos mesmo que seja no deserto, onde encontraremos novas soluções. (...) / Preciso que o Celso Amorim me ajude a fazer o filme aqui. É fundamental para minha saúde. Ele facilitou as coisas aqui em Portugal mas é bom você apoiar. Felizmente fofocas não nos separaram.

Sintra, 26 de abril de 1981 / Querido Cacá / (...) Escrevo diante de uma panavisão sobre o Atlântico camoniano e sebastianista do alto de uma montanha antes habitada por [Lord] Byron numa linda casa onde viveu Ferreira de Castro (...) as coisas vão bem, estou feliz no meu feudo à beiramar plantado vendo todos os dias naves partindo na construção do IV Império de Sebastião Ressuscitado... vou fazer com a RAl aqui em coprodução com os portugueses o NASCIMENTO DOS DEUSES (...) é possível realizar o Ciro e Alexandre aqui, há muita cultura árabe castelos etc. (...) / PS - o cinema português está prometendo... sinto-me mais ou menos em casa, boa cama, boa mesa, bom clima, transromantismo...

Sintra, 8 de junho de 1981 / Querido Celso / (...) Preciso saber de tudo rapidamente porque resta-me 50 dólares. Sá da Bandeira [Presidente do Instituto Português de Cinema] não me procura, o verão começa, a vida só recomeça em setembro. Claude está interessado, mas Sá da Bandeira ainda não se decidiu. / PRECISO DINHEIRO URGENTÍSSIMO - adiante-me sobre o contrato 2 MILHÕES e depois vamos acertar o resto até ao fim do ano. Caso a Embrafilmes não resolva meu problema, estarei definitivamente proletarizado, em suma, será difícil...

Sintra, 16 de julho de 1981 / Caro Tom [Luddy, produtor americano] / Estou escrevendo um novo roteiro: $O$ destino da humanidade. Vou acabar no dia 20 
de agosto. Meu produtor francês, Claude-Antoine, quer fazer o filme aqui. Portugal é bonito e poderei ter dinheiro em setembro do Instituto de Cinema Português. Embrafilme coproduz. Acho que posso fazer o filme em outubro. Aqui, no Sul, tenho sol durante novembro e dezembro. Preciso de 2 milhões de dólares e acho que Toscan du Plantier está interessado. Se não for possível aqui irei para Paris. O cenário do filme é uma grande cidade. (...) / Estou bem - ok. Posso trabalhar. Portugal é o Paraíso... / (...) Agora é 17 de julho. O Presidente do Instituto Português de Cinema, Sr. Sá da Bandeira, saiu! Crise com a secretaria de Cultura. Minha produção está parada... Mas eu escrevo roteiro. Talvez a crise esteja acabada em setembro...

Sabe-se hoje que Glauber Rocha não se beneficiou das vantagens deste acordo de coprodução luso-brasileiro. Em julho, apesar de concluída no mês anterior a primeira fase do argumento de $O$ Império do Napoleão, uma alteração na administração do Instituto Português de Cinema fez com que o financiamento prometido para o filme fosse suspenso. Poucos dias depois Glauber Rocha adoeceria. Foi hospitalizado a 3 de agosto e acabaria por falecer a 21 de agosto.

\section{Referências bibliográficas}

CELULÓIDE..., nº 197, maio de 1974.

Cinema Novo Português 1962-74. Lisboa: Cinemateca
Portuguesa, 1985.

BENTES, Ivana (org.). Cartas ao mundo. São Paulo: Companhia das Letras, 1997.

CARDOSO, Maurício. O Cinema Tricontinental de Glauber Rocha: política, estética e revolução (1969-1974). 2007. São Paulo. Tese de doutorado (História Social) USP, São Paulo/Paris X, Paris.

CUNHA, Paulo. Os filhos bastardos. Afirmação e reconhecimento do novo cinema português 1967-74. 2005. Coimbra. Dissertação de mestrado (História das Ideologias e Utopias Contemporâneas) - Universidade de Coimbra.

FIGUEIRÔA, Alexandre. Cinema Novo: a onda do jovem cinema e sua recepção na França. São Paulo: Papirus, 2004.

MATOS-CRUZ, José de. "Um imaginário luso-brasileiro". Camões. Revista de Leras e Culturas Lusófonas, n. ${ }^{\circ} 11,2000$. p. 142-159.

MELO, Jorge Silva (org.). O rio do ouro. Lisboa: Cinemateca Portuguesa, 1996. 
MONTEIRO, João César. "Entrevista com Glauber Rocha". Cinéfilo, n. ${ }^{\circ} 32,18$ de maio de 1974. p. 9-16.

PACHECO, Mário. "Um lindo lugar". In: Do próprio bolso. [197-?]. Disponível em: www.dopropriobolso.com.br/paginas_bolso/txt189.htm. Acessado em 27 de março de 2018.

PIERRA, Sylvie. Glauber Rocha. Campinas: Papirus, 1996.

SALES, Michelle. Em busca do um novo cinema português. Covilhã: Labcom, 2011.

SILVA, Regina. O Cinema brasileiro em Portugal. Contexto e análise da crítica acerca de filmes brasileiros publicada na imprensa lisboeta (1960-1999). 2006. Lisboa. Tese de doutorado (Ciências da Comunicação, Especialidade Cinema) Universidade Nova de Lisboa.

TURIGLIATTO, Roberto (org.). Paulo Rocha. Torino: Lindau, 1995. 